\title{
Patients with Myocardial Infarction and Normal Coronary Arteriogram*
}

\author{
V. Legrand, M.D.; M. Deliege, M.D.; L. Henrard, M.D.; \\ J. Boland, M.D.; and H. Kulbertus, M.D.
}

\begin{abstract}
Eighteen patients who survived an acute myocardial infarction were found to have a normal coronary arteriogram. Seven patients were younger than 35 years and six were female. The myocardial infarction was nontransmural in 11 cases. The mean follow-up was 21.6 months. Eleven patients developed residual chest pain at rest early after myocardial infarction. One, treated by beta-blockers, suffered a recurrent myocardial infarction. Eight became asymptomatic, and two improved under antispastic therapy. Another patient developed a severe form of variant angina three months after myocardial infarction; she died following plexectomy. Final-
\end{abstract}

M yocardial infarction is generally associated with obstructive coronary artery disease and thought to be the result of a permanent or transient vascular obstruction leading to myocardial necrosis. ${ }^{1}$ The development of selective coronary arteriography has revealed, however, that myocardial infarction may occur, in the absence of atherosclerotic obstructive coronary lesions, in patients with patent cor-

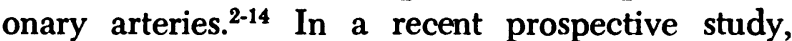
Betriu et al $^{12}$ found normal coronary arteries in 3 percent of patients surviving an acute myocardial infarction; it is thus a rare finding. Furthermore, the identification of patients with myocardial infarction and normal coronary arteries seems difficult as their epidemiologic profile is similar to that of patients with atherosclerotic process except for their younger age. ${ }^{4,9,12,14}$ As a consequence, the prognosis and follow-up is not better known than the physiopathologic process which leads to myocardial infarction in this subset of patients. The purpose of the present study was to evaluate the clinical profile of patients with myocardial infarction and normal coronary arteries; to discuss the possible causes of infarction in this group of patients; and to describe their follow-up and long-term prognosis.

\section{MeTHODS}

\section{Patient Selection}

From January 1978 to July $1981,1,727$ patients were ad-

- From the University of Liège School of Medicine, Department of Cardiology, Liège, Belgium.

Manuscript received April 13; revision accepted July 13

Reprint requests: Dr. Kulbertus, Cardiology, University

Hospital, 66 Bd de la Constitution, Liege, Belgium B-4020 ly, two patients experienced rare episodes of angina at rest. The stress ECG was negative in all cases. Provocative test for spasm was positive in three out of nine patients. Diffuse narrowing associated with chest pain was demonstrated in two patients at angiography. Thus, myocardial infarction and subsequent normal coronary angiogram are mainly found in young female patients, and infarction is often nontransmural. Clinical evidence of vasospastic phenomena and increased vasomotor tone are found in most patients. Whenever residual chest pain is controlled by antispastic therapy, the follow-up course seems benign.

mitted to the coronary care unit with a diagnosis of acute myocardial infarction. They met the following criteria: (1) history of prolonged chest pain; (2) typical ECG changes, and (3) characteristic rise and fall of serum enzyme values (creatine phosphokinase [CPK], glutamic oxaloacetic transaminase [SGOT], and lactic dehydrogenase [LDH]). The diagnosis of subendocardial infarction was made if the ECG showed persistent ischemic $T$ waves or persistent ST segment depression lasting longer than 48 hours without subsequent development of $Q$ waves; the diagnosis of transmural infarction included the first criteria but also required the evolution of $Q$ waves indicative of transmural necrosis ( $0.04 \mathrm{~s}$ duration and amplitude greater than 25 percent of the succeeding $R$ wave). A total of 236 patients (13.6 percent) died during hospitalization. Some 310 of the survivors under 65 years of age ( 28.3 percent) were subsequently submitted to coronary arteriography.

Angiography was performed for one or more of the following reasons: (1) residual ischemia demonstrated by typical angina pectoris, or positive exercise ECG and/or stress thallium ischemia (280 patients); (2) age under 35 (18 patients); (3) subendocardial infarction (86 patients); (4) malignant arrhythmias in the posthospital phase (ventricular tachycardia in three cases and frequent multifocal ventricular beats or doublets at exercise in two cases).

A normal coronary angiogram was obtained in 18 patients who constitute the present study group. Their distribution among the patients submitted to angiography is given on Table 1 .

\section{Clinical Evaluation}

On admission, each patient was interviewed on the circumstances of the event, past history of angina, smoking habits, and previous therapy. Serum glucose and lipids levels were measured after a 12-hour fast, three months after infarction. Patients with normal fasting glycemia were further submitted to a $100 \mathrm{~g}$ sugar ingestion with subsequent dosage of both glycemia and insulinemia to evaluate their glucose tolerance. Patients were considered hypertensive if they were receiving hypotensive drugs or if blood pressure 
Table 1-Patient Selection for Angiography

\begin{tabular}{|c|c|c|c|}
\hline Justification of Angiography & $\mathbf{N}$ & $\begin{array}{c}\text { Coronary } \\
\text { Normal, } \\
n=18 \\
\text { (Percent*) }\end{array}$ & $\begin{array}{c}\text { Arteries } \\
\text { Abnormal, } \\
n=292 \\
\left.\text { (Percent }^{*}\right)\end{array}$ \\
\hline (1) Residual ischemia & 282 & $9(3)$ & $273(97)$ \\
\hline (2) Age under 35 & 18 & $7(39)$ & $11(61)$ \\
\hline (3) Subendocardial infarction & 86 & $12(14)$ & $74(86)$ \\
\hline (4) Malignant arrhythmias & 5 & - & $5(100)$ \\
\hline$(1)+(2)$ & 8 & $2(25)$ & $6(75)$ \\
\hline$(1)+(3)$ & 69 & $5(7)$ & $64(93)$ \\
\hline$(2)+(3)$ & 7 & $5(71)$ & $2(29)$ \\
\hline$(1)+(2)+(3)$ & 3 & $2(67)$ & $1(33)$ \\
\hline
\end{tabular}

*Percentage of patients with normal or abnormal arteries according to the justification of angiography.

was greater than 160/95 mm Hg. Patients were reviewed at three months and every sixth month thereafter. The mean duration of follow-up was 21.6 months with a range of 6 to 42 months.

\section{Angiography}

Catheterization was performed using the Judkins technique at a mean delay of 70 days (range one to seven months) after infarction. The investigation included left ventriculography in right anterior oblique projection, selective left coronary angiography (six projections), and selective right coronary angiography (four projections). Left ventriculograms and coronary angiograms were read independently by at least two observers. Only patients with normal or near normal angiograms (irregularities of vessel wall with narrowings of less than 30 percent) were included in this study. Left ventricular ejection fractions were calculated using Simpson's formula with the aid of an automated system. Regional wall motion was assessed by comparison of the left ventricular end-diastolic and end-systolic silhouette according to the method of Ingels et al.15

\section{Exercise Test}

Three months after infarction, 16 patients were submitted to a bicycle ergometer test. A progressive multistage protocol (increment of $10 \mathrm{~W}$ per minute) was applied. The test was interrupted when fatigue, chest pain, shortness of breath, fall in blood pressure, or malignant arrhythmias developed, or when the maximal heart rate for age was reached. A standard 12-lead ECG was recorded before and every minute throughout the exercise. The test was ended five minutes after interruption of exercise. It was judged positive in the presence of $1 \mathrm{~mm}$ or more horizontal or downsloping ST depression for at least $0.08 \mathrm{~s}$.

\section{Provocative Test for Coronary Spasm}

A provocative test for coronary spasm was performed in the coronary care unit, according to the method described by Waters et al, ${ }^{16}$ in seven patients (cases $5,6,8,9,10$, $12,13)$ and during catheterization according to the technique of Heupler, ${ }^{17}$ in two patients (cases 1 and 18). All antispastic medications had been withdrawn for at least 12 hours with the exception of two patients (cases 5 and 13) who were receiving amiodarone, a drug recognized to have a long half-life. The test was considered positive if the patient developed typical chest pain relieved by nitroglycerine and accompanied by ECG changes consisting of ST elevation or depression of $1 \mathrm{~mm}$ or more from the control tracing.

\section{ResUlts}

\section{Clinical Characteristics (Table 2)}

Seven subjects ( 39 percent) were younger than 35 years and 6 ( 33 percent) were female. Among patients submitted to angiography in whom obstructive coronary disease was found, only 11 out of 292

Table 2-Clinical Characteristics

\begin{tabular}{|c|c|c|c|c|c|c|c|c|}
\hline \multirow{2}{*}{$\begin{array}{l}\text { Case } \\
\text { No. } \\
1\end{array}$} & \multirow{2}{*}{$\frac{\text { Age }(y r) / \operatorname{Sex}}{43 / F}$} & \multirow{2}{*}{$\frac{\text { Hypertension }}{-}$} & \multirow{2}{*}{$\begin{array}{c}\begin{array}{c}\text { Diabetes }(\mathrm{D}) \\
\text { or Glucose } \\
\text { Intolerance }(\mathrm{Gi})\end{array} \\
\mathbf{G i}\end{array}$} & \multirow{2}{*}{$\begin{array}{c}\begin{array}{c}\text { Cholesterol, } \\
\mathrm{g} / \mathrm{L}\end{array} \\
2.03\end{array}$} & \multirow{2}{*}{$\begin{array}{c}\text { Cigarettes } \\
\text { Smoking, } \\
\text { No./Day }\end{array}$} & \multicolumn{2}{|c|}{$\begin{array}{c}\text { Previous } \\
\text { Chest Pain } \\
\text { and Duration }\end{array}$} & \multirow{2}{*}{$\begin{array}{c}\text { Therapy Before } \\
\text { Myocardial Infarction } \\
\text { Pindolol nitrates }\end{array}$} \\
\hline & & & & & & + & 9 mo & \\
\hline 2 & $56 / F$ & + & - & 2.61 & 5 & + & $4 \mathrm{mo}$ & Dihydergotamine \\
\hline 3 & $30 / F$ & - & Gi & 1.41 & 25 & + & 3 days & - \\
\hline 4 & $28 / M$ & - & $\mathbf{G i}$ & 2.21 & 25 & + & 1 day & - \\
\hline 5 & $49 / M$ & + & $\mathbf{G i}$ & 1.65 & 60 & + & 4 days & Acetylsalicylic acid \\
\hline 6 & $19 / \mathrm{M}$ & - & - & 1.59 & $\mathbf{0}$ & + & 1 day & - \\
\hline 7 & $39 / \mathrm{M}$ & - & - & 2.25 & 0 & + & $20 \mathrm{mo}$ & Nitrates, prednisolone \\
\hline 8 & $59 / \mathbf{M}$ & - & - & 2.83 & 20 & + & 7 days & Nitrates \\
\hline 9 & $56 / F$ & - & - & 1.85 & $\mathbf{0}$ & - & - & - \\
\hline 10 & 30/M & + & - & 1.95 & 25 & + & 1 day & - \\
\hline 11 & $47 / M$ & - & Gi & 2.04 & 35 & $t$ & $+\mathrm{mo}$ & Propranolol \\
\hline 12 & 22/M & - & - & 2.53 & $\mathbf{0}$ & + & $3 \mathrm{mo}$ & Amphetamines \\
\hline 13 & $49 / M$ & - & D & 2.85 & 25 & - & - & Glibencamide \\
\hline 14 & $60 / M$ & + & - & 1.87 & 25 & + & 2 days & Chlorazepam \\
\hline 15 & $42 / F$ & - & - & 2.86 & 20 & + & $2 \mathrm{yr}$ & $\begin{array}{l}\text { Dihydergotamine } \\
\text { Nialamide }\end{array}$ \\
\hline 16 & $51 / \mathrm{M}$ & + & Gi & 2.51 & 5 & + & $5 \mathrm{yr}$ & - \\
\hline 17 & 33/M & - & Gi & 1.29 & 30 & + & $1 \mathrm{mo}$ & - \\
\hline 18 & $34 / M$ & - & - & 2.19 & 25 & - & - & - \\
\hline
\end{tabular}


( 4 percent) were younger than 35 ( $p<0.001$ ), and only 21 ( 7 percent) were female $(p<0.001)$. Fifteen patients described previous chest pain, often atypical, occurring mainly at rest or after exercise. In five instances, chest pain was first noted a few hours or days before the infarct; it lasted for about 30 minutes in two cases (no 4 and 6). Patient 17 had experienced one episode of chest pain of 15-minute duration one month before myocardial infarction. One individual (case 1) had chest pain at rest associated with ST depression in anterior leads $\left(V_{2}\right.$, $V_{3}, V_{4}$ ) and negative $T$ wave in lateral leads ( $V_{5}$, $\left.V_{6}, D_{1}, a V L\right)$ five days before the infarct.

\section{Data Related to the Acute Phase of the Infarct (Table 3)}

In three instances, strenuous exercise preceded the onset of the infarct. One further patient (case 2) developed myocardial infarction during an episode of acute hypertension ( $270 / 140 \mathrm{~mm} \mathrm{Hg}$ ); later investigations revealed a pheochromocytoma.

A high incidence of subendocardial infarcts (11 cases, 61 percent) was observed.

The clinical course was not benign in all instances: one patient (case 3) was admitted a few minutes after an episode of acute chest pain. She was found in cardiorespiratory arrest with persistent ventricular fibrillation and was resuscitated with success. Three others suffered ventricular tachycardia or fibrillation requiring electric countershock.

Eight patients described residual angina at rest 3 to 16 days after their myocardial infarction. The ST changes during chest pain were noted in two instances and consisted in ST depression in anterior leads in patient 11 and ST elevation in inferior leads in patient 14 .

\section{Follow-Up Data (Table 4)}

Seven of the eight patients with early residual angina received antispastic medications (nifedipine, verapamil, amiodarone, nitrates). Five became asymptomatic and two ( 8 and 11) still described chest pain at rest or exercise without demonstrable ECG changes. The last patient (case 7) with early residual angina first received propranolol; 67 days later, he developed a recurrent transmural anterior myocardial infarction. Thereafter, he still had chest pain despite nifedipine and amiodarone. This patient also had a hematologic disorder (Vaquez disease) since the age of 20 years; he developed myelo-

Table 3-Characteristic Features of the Infarct*

\begin{tabular}{|c|c|c|c|c|c|c|c|c|c|}
\hline $\begin{array}{l}\text { Case } \\
\text { No. }\end{array}$ & $\begin{array}{l}\text { Circumstances } \\
\text { of Infarct }\end{array}$ & Location & $\begin{array}{c}\text { Peak } \\
\text { CPK, } \\
\text { IU }\end{array}$ & $\begin{array}{l}\text { Peak } \\
\text { SGOT, } \\
\text { IU }\end{array}$ & Shock & Arrhythmias & $\begin{array}{l}\text { Conduction } \\
\text { Disturbances }\end{array}$ & $\begin{array}{l}\text { Ventricular } \\
\text { Failure }\end{array}$ & $\begin{array}{c}\text { Residual } \\
\text { Angina } \\
\text { (Delay from } \\
\text { Infarction) }\end{array}$ \\
\hline 1 & Rest & SE ant sept & 627 & 195 & No & No & No & No & No \\
\hline 2 & $\begin{array}{l}\text { Episode of } \\
\text { paroxysmal } \\
\text { HTA }\end{array}$ & SE inf lat & 444 & 154 & No & VPBs & No & LVF K2 & No \\
\hline 3 & Mild stress & TM ant lat & 8866 & 1026 & $\begin{array}{l}\text { Yes } \\
\text { (CRA) }\end{array}$ & VF, VPBs & No & LVF K3 & No \\
\hline 4 & Rest & TM ant & 590 & 39 & No & No & No & No & No \\
\hline 5 & Mild stress & TM ant lat & 2229 & 396 & No & VPBs & LBBB & LVF K2 & No \\
\hline 6 & $\begin{array}{l}\text { After stren- } \\
\text { uous stress }\end{array}$ & SE inf & 1670 & 290 & No & No & No & No & No \\
\hline 7 & Rest & SE ant lat & 1040 & 136 & No & No & No & LVF K2 & Yes 3 days \\
\hline 8 & Rest & TM inf & 1046 & 199 & No & VF, VPBs & No & LVF K2 & Yes 4 days \\
\hline 9 & $\begin{array}{l}\text { After stren- } \\
\text { uous stress }\end{array}$ & SE ant & 196 & 55 & No & No & No & No & No \\
\hline 10 & Sleep & SE inf & 533 & 101 & No & No & No & No & Yes 16 days \\
\hline 11 & Rest & SE inf lat & 1243 & 211 & No & VT, VPBs & No & No & Yes 7 days \\
\hline 12 & $\begin{array}{l}\text { After stren- } \\
\text { uous stress }\end{array}$ & SE ant & 700 & 73 & No & VPBs & No & LVF K2 & No \\
\hline 13 & Rest & TM inf & 673 & 47 & No & No & No & No & Yes 4 days \\
\hline 14 & Sleep & TM ant sept & 3069 & 531 & No & VT, VPBs & No & LVF K2 & Yes 3 days \\
\hline 15 & Rest & SE inf lat & 312 & 51 & No & No & No & No & No \\
\hline 16 & Rest & TM ant sept inf & 1340 & 342 & No & VPBs & No & LVF K2 & Yes 4 days \\
\hline 17 & Rest & SE sept & 630 & 68 & No & No & No & No & No \\
\hline 18 & Rest & SE inf & 414 & 99 & No & VPBs & No & No & Yes 7 days \\
\hline
\end{tabular}

*HTA indicates arterial hypertension; SE, subendocardial; TM, transmural; ant, anterior; sept, septal; lat, lateral; inf, inferior; CRA, cardiorespiratory arrest; VPB, ventricular premature beats; VF, ventricular fibrillation; VT, ventricular tachycardia; LBBB, left bundle branch block; LVF, left ventricular failure; and K1, K2, K3, functional class according to Killip's classification $(1,2,3)^{38}$ 
Table 4-Follow- $U_{P}$ and Resules of Investigation*

\begin{tabular}{|c|c|c|c|c|c|}
\hline Case No. & $\begin{array}{l}\text { Residual Angina Pectoris } \\
\text { or Atypical Chest Pain } \\
\text { (Delay From Infarct) }\end{array}$ & Therapy Instituted & Subsequent Follow-Up & Stress Test & $\begin{array}{l}\text { Provocative Test } \\
\text { for Bpasm }\end{array}$ \\
\hline 1 & Angina pectoris, 2 mo & Nif, Am, Nitr & Died after plexectomy & - & + \\
\hline 2 & No & $\begin{array}{l}\text { Pheochromocytoms } \\
\text { resected }\end{array}$ & Asymptomatic & - & NP \\
\hline 3 & Atypical chest pain, 3 mo & Nif, digox, diur & Atypical chest pain & - & NP \\
\hline 4 & Atypical chest pain, 6 mo & Nif, Nitr & Asymptomatic & - & NP \\
\hline 5 & Atypical chest pain, 8 mo & Nif, Am, Nitr, digox & Asymptomatic & - & - \\
\hline 6 & No & - & Asymptomatic & - & + \\
\hline 7 & $\begin{array}{l}\text { Angina pectoris acute } \\
\text { stage. Recurrent infarct, } \\
67 \text { days }\end{array}$ & $\begin{array}{l}\text { Nitr, pindolol, } \\
\text { Nif, Am }\end{array}$ & Atypical chest pain & NP & NP \\
\hline 8 & $\begin{array}{l}\text { Angina pectoris acute } \\
\text { stage }\end{array}$ & Nif, Nitr & Angina pectoris & - & + \\
\hline 9 & $\begin{array}{l}\text { Angina pectoris, } \\
9 \text { mo (one episode) }\end{array}$ & - & Asymptomatic & - & - \\
\hline 10 & $\begin{array}{l}\text { Angina pectoris acute } \\
\text { stage }\end{array}$ & Nif & Asymptomatic & - & - \\
\hline 11 & $\begin{array}{l}\text { Angina pectoris acute } \\
\text { stage }\end{array}$ & Nif, Nitr & Angina pectoris & - & NP \\
\hline 12 & $\begin{array}{l}\text { Angina pectoris, } \\
6 \text { mo (one episode) }\end{array}$ & - & Asymptomatic & - & - \\
\hline 13 & $\begin{array}{l}\text { Angina pectoris acute } \\
\text { stage }\end{array}$ & Am & Asymptomatic & - & - \\
\hline 14 & $\begin{array}{l}\text { Angina pectoris acute } \\
\text { stage }\end{array}$ & Nif, Verap, Nitr & Asymptomatic & NP & NP \\
\hline 15 & No & Nif & Asymptomatic & - & - \\
\hline 16 & $\begin{array}{l}\text { Angina pectoris acute } \\
\text { stage }\end{array}$ & Am & Atypical chest pain & - & $\mathbf{N P}$ \\
\hline 17 & No & - & Asymptomatic & - & NP \\
\hline 18 & $\begin{array}{l}\text { Angina pectoris acute } \\
\text { stage }\end{array}$ & Nitr, Nif & Asymptomatic & - & - \\
\hline
\end{tabular}

*Nif indicates nifedipine; Am, amiodarone; Nitr, nitrates; digox, digoxine; diur, diuretics; Verap, verapamil; and NP, n o performed.

sclerosis and died 11 months after his first infarct.

Three other patients developed late recurrent angina. In patient 1 , it appeared at three months and was associated with ST-segment elevation in the inferior leads. The investigation showed a hypokinetic anterior wall, normal coronary vessels but spontaneous spasm of the right coronary artery. Despite medical management (nifedipine, amiodarone, nitrates), this patient remained symptomatic, and 24 months later, a repeat catheterization was performed. The coronary arteries were still normal, and spasm of the right coronary artery was induced by ergonovine. Plexectomy was performed, but the patient died in intractable ventricular fibrillation. Patient 9 experienced one episode of anginal pain at rest with ST-depression at nine months. She remained asymptomatic thereafter. Patient 12 was readmitted for typical anginal chest pain without ST changes or enzyme elevation at six months.

Finally, patients 3, 4, and 5 described atypical chest pain which improved or disappeared with nifedipine.

\section{Stress Test}

A submaximal stress test was obtained in $16 \mathrm{pa}$ tients. It was negative in all instances; however, two patients ( 8 and 11 ) developed chest pain without ST changes.

\section{Provocative Test for Spasm}

Seven patients had a provocative test for spasm in the coronary care unit one day after catheterization. Two (cases 6 and 8 ) had a positive response (ST depression with chest pain). Two tests were performed during catheterization: one (case 1) showed proximal obstruction of the right coronary artery associated with angina and ST elevation and the other (case 18) revealed severe, diffuse narrowing of the right coronary artery associated with chest pain, without ST changes (Fig 1).

\section{Angiography (Table 5)}

The arteriograms were truly normal in 13 patients 


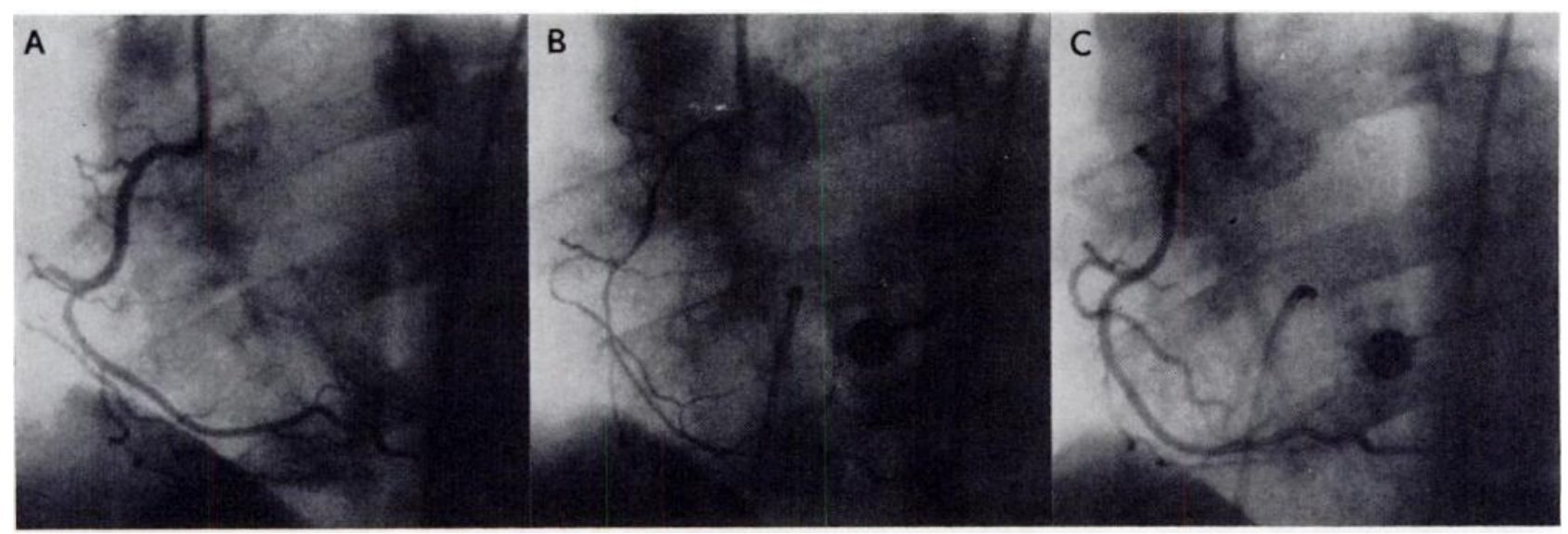

Figure 1. Angiography of the right coronary artery in left anterior oblique position obtained in patient $\mathrm{nr}$ 18. $\mathrm{A}$ is before provocative test for spasm; $\mathrm{B}$, after intravenous infusion of $0.1 \mathrm{mg}$ ergonovine; and $\mathrm{C}$, after intracoronary injection of nitroglycerine. The injection of ergonovine produced a severe diffuse narrowing of the artery associated with chest pain. After injection of nitroglycerin, the artery dilated and chest pain disappeared.

and showed minimal irregularities on the infarct related vessel in four cases $(8,11,12$, and 13$)$, or on another vessel in one case $(16)$.

The ventriculograms were normal in six cases $(6$, $9,10,13,17$, and 18) and showed contraction abnormalities corresponding to the infarct seen on the ECG in the other cases.

No complication occurred during catheterization. However, one patient (case 4) developed diffuse narrowing of the left coronary artery with angina pectoris and significant ST segment elevation after the first intracoronary injection of contrast medium, and patient 1 had at first catheterization spontaneous spasm of the right coronary artery with STsegment elevation. All signs of ischemia disappeared after sublingual administration of nitroglycerin.

\section{Discussion}

\section{Prevalence and Clinical Profile}

The prevalence of patients with myocardial infarction who have normal or near normal coronary arteries varies from 1 percent to 12 percent according to the mode of investigation and the population studied. ${ }^{2-14}$ Recent prospective studies ${ }^{12,18,19}$ indicate that survivors of acute myocardial infarction have normal coronary arteries in 1 percent to 3 percent of cases. In our population, the prevalence of patients with normal vessels was 6 percent, but this being a retrospective study, the patients submitted to coronary arteriography were a selected subgroup that was not necessarily representative of the whole

Table 5-Angiographic Findings*

\begin{tabular}{|c|c|c|c|c|c|c|c|}
\hline $\begin{array}{l}\text { Case } \\
\text { No. }\end{array}$ & ECG & $\begin{array}{l}\text { Time from } \\
\text { MI (mo) }\end{array}$ & LAD & LCX & RCA & Ventriculogram & EF, \% \\
\hline 1 & SE anteroseptal & 4 & $\mathbf{N}$ & $\mathbf{N}$ & $\mathbf{N}$ & Anterior hypokinesia & 64 \\
\hline 2 & SE inferolateral & 2 & $\mathbf{N}$ & $\mathbf{N}$ & $\mathbf{N}$ & Anterior hypokinesia & 58 \\
\hline 3 & TM anterolateral & 6 & $\mathbf{N}$ & $\mathbf{N}$ & $\mathbf{N}$ & Anterior akinesia - apical dyskinesia & 44 \\
\hline 4 & TM anterior & 3 & $\mathbf{N}$ & $\mathbf{N}$ & $\mathbf{N}$ & Apical akinesia & 56 \\
\hline 5 & TM anterolateral & 7 & $\mathbf{N}$ & $\mathbf{N}$ & $\mathbf{N}$ & Anterolateral akinesia & 36 \\
\hline 6 & SE inferior & 1 & $\mathbf{N}$ & $\mathbf{N}$ & $\mathbf{N}$ & Normal & 72 \\
\hline 7 & SE anterolateral & 3 & $\mathbf{N}$ & $\mathbf{N}$ & $\mathbf{N}$ & Anterior akinesia & 59 \\
\hline 8 & TM inferior & 2 & $\mathbf{N}$ & $\mathbf{N}$ & irreg $<30 \%$ & Inferior hypokinesia & 60 \\
\hline 9 & SE anterior & 1 & $\mathbf{N}$ & $\mathbf{N}$ & $\mathbf{N}$ & Normal & 75 \\
\hline 10 & SE inferior & 1 & $\mathbf{N}$ & $\mathbf{N}$ & $\mathbf{N}$ & Normal & 55 \\
\hline 11 & SE inferolateral & 3 & irreg $<30 \%$ & $\mathbf{N}$ & $\mathbf{N}$ & Anteroapical hypokinesia & 60 \\
\hline 12 & SE anterior & 2 & irreg $<30 \%$ & $\mathbf{N}$ & $\mathbf{N}$ & Anterior hypokinesia & 48 \\
\hline 13 & TM inferior & 1 & $\mathbf{N}$ & irreg $<30 \%$ & $\mathbf{N}$ & Normal & 70 \\
\hline 14 & TM anteroseptal & 1 & $\mathbf{N}$ & $\mathbf{N}$ & $\mathbf{N}$ & Anterior akinesia & 43 \\
\hline 15 & SE infero-lateral & 1 & $\mathbf{N}$ & $\mathbf{N}$ & $\mathbf{N}$ & Anterolateral hypokinesia & 61 \\
\hline 16 & TM anteroseptal & 1 & $\mathbf{N}$ & irreg $<30 \%$ & $\mathbf{N}$ & Anterior akinesia & 50 \\
\hline 17 & SE septal & 1 & $\mathbf{N}$ & $\mathbf{N}$ & $\mathbf{N}$ & Normal & 63 \\
\hline 18 & SE inferior & 1 & $\mathbf{N}$ & $\mathbf{N}$ & $\mathbf{N}$ & Normal & 61 \\
\hline
\end{tabular}

*MI indicates myocardial infarction; LAD, left anterior descending coronary artery; RCA, right coronary artery; N, normal; SE, subendocardial; TM, transmural; LCX, left circumflex coronary artery; and EF, ejection fraction. 
population recovering from acute myocardial infarction.

Our patients were characterized by their younger age as compared to patients with myocardial infarction and obstructive coronary disease. This has also been noted by others who found that 16 percent ${ }^{14}$ or even 45 percent ${ }^{12}$ of infarcts associated with normal coronary arteriogram occurred among patients under 35 years of age. Another characteristic of the studied subjects is the high proportion of women (33 percent), a feature which was not found in other series. ${ }^{9,10}$

Rosenblatt and Selzer ${ }^{9}$ pointed to the low incidence of risk factors among patients with infarction and normal angiogram, and Mc Kenna et $\mathrm{al}^{10} \mathrm{em}$ phasized the role of smoking. Among our patients, the analysis of risk factors failed to show any salient feature. Clinical, laboratory, and ECG features of myocardial infarction were indistinguishable from those of patients with obstructive atherosclerotic coronary disease (Table 3 ). However, the incidence of patients having nontransmural myocardial infarction was higher than that in previously reported similar studies ${ }^{9,12}$ and in the whole population of patients hospitalized in our unit for acute myocardial infarction $(380 / 1,727)(p<0.001)$.

\section{Limitations of Angiographic Findings}

Since coronary angiographic findings obtained one to seven months after the clinical episode of infarct may be different from those of the acute stage, precise information concerning the anatomy of the arteries at the time of infarction is lacking.

Regression of pre-existing obstructive atherosclerotic lesions has been demonstrated in animal studies and might occur in man. ${ }^{20}$ However, such an evolution is slow and probably requires several months as suggested by the study of Pichard et $\mathrm{al}^{21}$ who found a significant reduction of obstructed coronary vessels in the chronic phase of myocardial infarction only after the sixth month. In our population, with the exception of four patients, the angiogram was performed within the third month following the myocardial infarction. Thus, regression of pre-existing significant obstructive coronary lesions seems unlikely.

Temporary occlusion of the coronary arteries has been reported in cases of vasospastic angina, and severe prolonged spasm may lead to myocardial infarction. ${ }^{22,23}$ In such cases, angiography performed after the acute event may reveal patent coronary arteries. ${ }^{13}$

Thromboembolic mechanisms are often associated with acute myocardial infarction and obstruction or narrowing of a coronary artery by a fresh thrombus is frequently seen at autopsy of patients dying from acute myocardial infarction. ${ }^{1}$ However, recanalization of an initially obstructed vessel may be obtained by selective intracoronary thrombolysis with streptokinase. ${ }^{24}$ Moreover, clot lysis may also occur spontaneously as a result of physiologic thrombolysis. Thus, the thrombus or embolus occluding a coronary artery at the early stage of myocardial infarction may well disappear. In the absence of an underlying atherosclerotic obstructive lesion, the restoration of the lumen may be complete.

Another limitation of the angiographic evaluation is the misreading of coronary angiograms. Occasionally, a coronary lesion may be masked or underestimated, particularly if eccentric. In four patients, the infarct-related vessel was not truly normal, and minimal wall irregularities resulting in less than 30 percent obstruction were noted. Even if the lesion was underestimated, it is unlikely that significant narrowings were present and the use of multiple projections including angulated views reduces the possible pitfalls.

\section{Evidence of Spasm or Abnormal Coronary Tone}

Clinical angiographic and ECG evidence of excessive arterial coronary vasomotion or coronary spasm were found in several of our patients. Six individuals ( 33 percent) had evidence of spasm either spontaneous (cases 1, 9, 11, and 14) or induced by ergonovine (cases 6 and 8 ), accompanied by chest pain and ST changes. The relation between coronary spasm and myocardial infarction has been widely discussed, ${ }^{22,23}$ and in a recent study, ${ }^{25}$ Heupler observed that myocardial infarction occurred in 7 percent of patients (two out of $30 \mathrm{pa}$ tients) with normal coronary arteriograms and vasospastic angina.

Among the 12 other patients, focal coronary spasm was not demonstrated in spite of residual chest pain. Nevertheless, it is worthy of note that in eight of 11 patients in whom they were tried, calcium antagonists suppressed or reduced residual chest pain, while beta-blockers were ineffective or worsened the symptoms. In addition, during coronary angiography, two patients experienced chest pain associated with diffuse narrowing and slow filling of their coronary arteries (spontaneously in one case and after $0.1 \mathrm{mg}$ ergonovine, in the other). In both cases, symptoms disappeared and coronary arteries dilated after administration of nitrates suggesting a diffuse increase in arteriolar resistances.

Factors known to increase vascular tone or to induce spasm were noted in four patients before the infarct. Three were receiving drugs such as dihydergotamine, nialamid, or amphetamines recog- 
nized for their vasoconstrictive effects. ${ }^{25}$ The last patient suffered from a pheochromocytoma and an elevated vasomotor tone induced by alpha-adrenergic stimulation could also be expected. Indeed, after tumor resection, the patient did not experience chest pain on exercise even for a rate-pressure product similar to that achieved during the paroxysmal hypertensive episodes.

It has been demonstrated that increased vasomotor tone may have profound hydraulic effects by increasing arteriolar resistances. ${ }^{26,27}$ If no fixed stenoses or focal spasm are superimposed, a diffuse reduction of coronary flow rather than a regional ischemia may be induced. It can be hypothetized that in some patients, the autoregulatory control of coronary flow is disturbed with inadequate decrease in arterial resistances. In such patients, the reduction of coronary flow might become critical and induce a moderate diffuse ischemia, not accompanied by significant ECG alterations but associated with chest pain improved by nitrates or calcium antagonists.

As changes in vasomotor tone are often spontaneous and vary with time, ${ }^{27-29}$ it may be difficult to demonstrate abnormal vasomotion. Moreover, the response to the ergonovine test may be either negative or nonspecific in the absence of focal spasm..$^{25,30}$ Determination of coronary blood flow and resistances during cold pressure test ${ }^{81}$ or after drug administration ${ }^{32}$ is an interesting approach to study this phenomenon. It should be envisaged in patients with myocardial infarction and normal coronary arteries.

\section{Mechanisms of Infarction}

The pathogenetic mechanism of acute myocardial infarction remains largely speculative. ${ }^{1,8,12}$ However, recent studies in which coronary arteriography was performed in the early stages of myocardial infarction have always disclosed severe narrowing or complete obstruction of at least one of the three major arteries. ${ }^{33,34}$ Later controls have, in some cases, demonstrated near normal arteries with regression of the initial narrowing, ${ }^{35}$ and angiograms performed six hours after the onset of symptoms reveal a significantly lower incidence of total occlusion than those performed within the first six hours. ${ }^{30}$ In postmortem studies, thrombi are found in only 10 percent of patients with subendocardial infarcts, while they are observed in more than 60 percent of patients with transmural infarcts. As suggested by Alpert and Braunwald, ${ }^{1}$ thrombosis may be a secondary event in patients with subendocardial necrosis. In such patients, a severe reduction of coronary blood flow due to coronary stenosis or coro- nary spasm or both probably constitutes the mechanisms of myocardial infarction. The high incidence of subendocardial necrosis and the absence of organic coronary narrowing in our study group suggest that coronary spasm might also play a major role in the genesis of infarction among patients with normal angiogram. Thus, it may be postulated that the infarction is initiated either by a prolonged vasospasm (or increased vasomotor tone) with consequent blood stagnation, or by an aggregation of platelets over an ulcerated intimal atherosclerotic lesion. The consequent platelet aggregation is accompanied by thromboxane A2 release with potentiation or initiation of vasoconstriction leading to ischemia or necrosis. ${ }^{37} \mathrm{~A}$ thrombus may eventually form, this last condition probably resulting in a transmural necrosis. In a later phase, lysis and recanalization might occur, restoring an apparently normal coronary tree. Some cases of myocardial infarction related to coronary embolism have been reported, ${ }^{6}$ however, in the absence of an embolic disease, this mechanism does not seem likely.

\section{Clinical Implications}

Acute myocardial infarction may occur in patients with angiographically-normal coronary arteries. These patients are generally younger and frequently develop subendocardial necrosis. Coronary spasm may be a significant factor in the pathogenesis of this type of infarct, but is not observed in all subjects. However, clinical data suggestive of increased vasomotor tone are often demonstrated before and after the acute event. This may explain the high frequency of residual chest pain and the efficacy of antispastic medications on symptoms. The prognosis after myocardial infarction seems good if the spastic phenomenon is controlled by medication. In this series, only one cardiac death and one recurrent myocardial infarction were noted; the period of follow-up (mean 21.6 months) was, however, rather short.

Angiographic evaluation of young patients recovering from acute myocardial infarction is warranted in order to identify those without significant obstructive disease. Ergonovine test may be performed during catheterization in order to unmask a focal spasm, but even if the test is negative, antispastic therapy should be instituted at least among patients with residual chest pain.

\section{REFERENCES}

1 Alpert JS, Braunwald E. Pathological and clinical manifestations of acute myocardial infarction. In: Braunwald E, ed. Heart disease, Vol. 2. Philadelphia: WB Saunders, 1980 
2 Likoff W. Myocardial infarction in subiects with normal coronary arteriograms. Am J Cardiol 1971; 28:742-43

3 Kimbiris D, Segal BL, Munir M, Katz M, Likoff W. Myocardial infarction in patients with normal patent coronary arteries as visualized by cinearteriography. Am J Cardiol 1972; 29:724-28

4 Khan H, Haywood LJ. Myocardial infarction in nine patients with radiographically patent coronary arteries. N Engl J Med 1974; 291:427-31

5 Ciraulo DA. Recurrent myocardial infarction and angina in a woman with normal coronary angiograms. Am J Cardiol 1975; 35:923-26

6 Arnett EN, Roberts WC. Acute myocardial infarction and angiographically normal coronary arteries: an unproven combination. Circulation 1976; 53:395-400

7 Chesler E, Matison RE, Lakier JB, Popcock WA, Obel IWP, Barlow JB. Acute myocardial infarction with normal coronary arteries. Circulation 1976; 54:203-09

8 Oliva PB, Breckinridge JC. Acute myocardial infarction with normal or near normal coronary arteries. Am J Cardiol 1977; 40:1000-07

9 Rosenblatt A, Selzer A. The nature and clinical features of myocardial infarction with normal coronary arteriograms. Circulation 1977; 55:578-80

10 McKenna WJ, Chew CYC, Oakley CM. Myocardial infarction with normal coronary angiogram. Br Heart J 1980; 43:493-98

11 Eliot RS, Baroldi G, Leone A. Necropsy studies in myocardial infarction with minimal or no coronary luminal reduction due to atherosclerosis. Circulation 1974; 49: 1127-31

12 Betriu A, Pare JC, Sanz GA, Casals F, Magrina J, Castaner A, et al. Myocardial infarction with normal coronary arteries: a prospective clinical-angiographic study. Am J Cardiol 1981; 48:28-32

13 Strong JP. Myocardial infarction in patients with patent coronary bed. In: Mason DJ, Neri Semeri GG, Oliver MF, eds. Myocardial infarction, Vol 2. Amsterdam: Excerpta Medica, 1979

14 Thompson SI, Vieweg WVR, Alpert JS, Hagan AD. Incidence and age distribution of patients with myocardial infarction and normal coronary arteriograms. Catheter Cardiovasc Diag 1977; 3:1-7

15 Ingels NB, Daughters GT, Stinson EB, Alderman EL. Evaluation of methods for quantitating left ventricular segmental wall motion in man using myocardial markers as a standard. Circulation 1980; 61:966-72

16 Waters DD, Theroux P, Szlachcic J, Dauwe F, Crittin J, Bonam $\mathbf{R}$, et al. Ergonovine testing in a coronary care unit environment. Am J Cardiol 1980; 46:922-30

17 Heupler FA. Provocative testing for coronary arterial spasm risk method and rationale. Am J Cardiol 1980; 46:335-40

18 Turner JD, Rogers WJ, Mantle JA, Rackley CE, Russell RO. Coronary angiography soon after myocardial infarction. Chest 1980; 77:58-64

19 Bertrand ME, Lefebvre M, Laisne CL, Rousseau MF, Carre AG, Lekieffre JP. Coronary arteriography in acute transmural myocardial infarction. Am Heart J 1979; 97: 61-69

20 Malinow MR. Regression of atherosclerosis in human: fact or myth? Circulation $1981 ; 64: 1-3$

21 Pichard A, Ziff C, Rentrop KP, Karsch K, Wiener I, Teichholz LE, et al. Incidence of total coronary occlusion in the chronic phase of myocardial infarction. Cir- culation 1981; 64(suppl IV):107

22 Maseri A, L'Abbate A, Baroldi G, Chierchia S, Marzille $\mathrm{M}$, Ballestra AM, et al. Coronary vasospasm as a possible cause of myocardial infarction. N Engl J Med 1978; 299: 1271-77

23 Oliva PB, Breckinridge JC. Arteriographic evidence of coronary arterial spasm in acute myocardial infarction. Circulation 1977; 56:366-74

24 Mason DT. International experience with percutaneous transluminal coronary recanalization by streptokinase thrombolysis reperfusion in acute myocardial infarction: new safe, landmark therapeutic approach salvaging ischemic muscle and improving ventricular function. Am Heart J 1981; 102:1126-33

25 Heupler RA. Syndrome of symptomatic coronary arterial spasm with nearly normal coronary arteriograms. Am J Cardiol 1980; 45:873-81

26 Gould KL. Dynamic coronary stenosis. Am J Cardiol 1980; 45:286-92

27 Epstein SE, Talbot TL. Dynamic coronary tone in precipitation, exacerbation and relief of angina pectoris. Am J Cardiol 1981; 48:797-803

28 Yasue HR, Omote S, Takizawa A, Nagao M, Miwa K, Tanaka S. Circadian variation of exercise capacity in patients with Prinzmetal's variant angina: the role of exercise-induced coronary arterial spasm. Circulation 1978; 59:938-48

29 Waters DD, Szlachcic J, Theroux P, Dauwe F, Mizgala HF. Ergonovine testing to detect spontaneous remissions of variant angina during long term treatment with calcium antagonist drug. Am J Cardiol 1981; 47:179-84

30 Magder SA, Johnstone DE, Huckell VF, Adelman AG. Experience with ergonovine provocative testing for coronary arterial spasm. Chest 1981; 79:638-46

31 Mudge GH, Grossman W, Mills RM, Lesch M, Braunwald $E$. Reflex increase in coronary vascular resistances in patients with ischemic heart disease. $N$ Engl J Med 1976; 295: 1333-37

32 Gunther S, Green L, Muller JE, Mudge GH, Grossman W. Prevention by nifedipine of abnormal coronary vasoconstriction in patients with coronary artery disease. Circulation 1981; 63:849-55

33 Rentrop P, Blanke H, Karsch R, Kaiser H, Köstering H, Leitz $\mathrm{K}$. Selective intracoronary thrombolysis in acute myocardial infarction and unstable angina pectoris. Circulation $1981 ; 63: 307-17$

34 Mathey DG, Kuch KH, Tilsner V, Krebher HJ, Bleifeld W. Nonsurgical coronary artery recanalization after acute transmural myocardial infarction. Circulation 1981; 63: 489-97

35 Reduto LA, Smalling RW, Freund GG, Gould KL. Intracoronary infusion of streptokinase in patients with acute myocardial infarction: effects of reperfusion on left ventricular performance. Am J Cardiol 1981; 48 : 403-09

36 De Wood MA, Spores J, Notske R, Mouser LT, Burroughs $\mathrm{R}$, Golden MS, et al. Prevalence of total coronary occlusion during the early hours of transmural infarction. N Engl J Med 1980; 303:897-901

37 Needleman P, Kulkarni PS, Raz A. Coronary tone modulation: formation and actions of prostaglandins endoperioxides and thromboxanes. Science 1977; 195:409-12

38 Killip T, Kimball JT. Treatment of myocardial infarction in a coronary care unit: a two years experience with 250 patients. Am J Cardiol 1969; 20:457-64 